Keywords: Teaching psychiatry; Innovation; Medical students; Performance; Satisfaction.

\title{
Innovative methods in teaching psychiatry to medical students
}

\author{
Antonio Lobo ${ }^{*, \star \star \star, \star \star \star \star \star, \star \star \star \star \star *}$ \\ Concepción de-la-Cámara $a^{\star, \star \star *, \star \star \star, \star \star \star \star \star, \star \star \star \star \star \star}$ \\ Ricardo Campos ${ }^{\star, \star \star *, \star \star \star, \star \star \star \star \star, \star \star \star \star \star \star}$ \\ Tirso Ventura ${ }^{*, * *, * * * *, * * \star *, * \star * * * *}$ \\ Carlos Marco

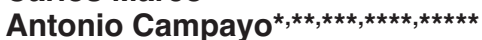 \\ Federico Dourdil ${ }^{\dagger *, * *, * \star *}$ \\ Mari Fé Barcones ${ }^{\star, \star \star \star \star, \star \star \star \star \star,, \star \star \star \star \star \star}$ \\ Pedro Saz ${ }^{\star, \star \star \star, * \star \star \star \star, \star \star \star \star \star \star}$ \\ * Department of Medicine and Psychiatry, \\ University of Zaragoza, Zaragoza \\ ** Hospital Clínico Universitario, Zaragoza \\ *** Instituto de Investigación Sanitaria de \\ Aragón (IIS Aragón), Zaragoza \\ **** Centro de Investigación Biomédica en \\ Red de Salud Mental (CIBERSAM), Madrid \\ ***** Faculty of Medicine, University \\ of Zaragoza, Zaragoza

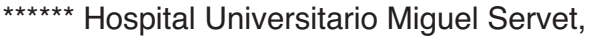 \\ Zaragoza \\ SPAIN
}

\begin{abstract}
Background and Objectives: To test the conjecture that the innovative method to teach psychosomatic psychiatry previously reported will be confirmed as beneficial in the training of medical students in the field of general psychiatry.

Methods: The emphasis in this course is placed on the discussion of clinical cases, bedside clinical teaching, and a research-oriented part. The "Innovative Teaching Plan" (ITP) is intended to train student-leaders to guide small groups (SG) of students. The results of an intensive clerkship on bedside teaching are also studied. Trainee performance was assessed by the marks in the final examination, and a reliable and valid tool, the Medical Teaching Quality Questionnaire (MTQQ) was used to document trainee satisfaction. The results of five academic courses are presented in this report.

Results: External experts consulted assured that the content of the course was adequate. Eight hundred and thirty eight medical students have completed the learning course in the study period, and 418 (one of the two groups) completed the evaluation with the MTQQ.

Most items related to the students' satisfaction were rated "high" or "very high", including the items asking about the usefulness of the course for physicians, the quality of the teaching methods and the bedside teaching. In relation to innovation, the discussion of
\end{abstract}


clinical cases in small groups was also very satisfactory and the "enhancement of a researcher's mind" was rated "high" or "very high" by $1 / 3$ rd of medical students. The utility of the yearly evaluation of the quality of teaching methods was supported by results showing that items scored not favourably in the initial evaluation were considerably improved in the follow-up evaluations, when modifications in the method were introduced.

Conclusions: Good performance and high satisfaction of medical students was documented in a course on general psychiatry. Lessons may be drawn to inform about efficient and effective ways of teaching and learning this subject.

Received: 9 January 2015

Revised: 15 February 2015

Accepted: 20 February 2015

\section{Introduction}

Psychiatry is a crucial discipline in the standard teaching of psychological medicine aspects of interest for general physicians ${ }^{1}$. Furthermore, some previous reports acknowledge the increasing demand for improved skills by medical graduates in the psychosocial aspects of medical care ${ }^{2}$. It is in this setting that interest in novel methods of teaching have emerged. For example, the beneficial effects of incorporating team learning into the psychiatry clerkship have been suggested by some authors ${ }^{3}$. Other authors have used a novel peer-peer learning activity with medical students, encompassing a specialist psychiatrist-general practitioner (GP) dyadic interchange of letters to enhance students' appreciation of the intricacies of the discipline $^{4}$. On the other hand, several reports underlie the relevance of problem-solving methods in this setting 5 .

The importance of research to improve the results of teaching should not be underestimated, since it is useful, for example, to identify problems in need of remedial actions. A systematic review identified that a mix of positive and negative attitudes toward psychiatry: while overall, the attitudes were considered to be positive, psychiatry as a career choice was rated poorly and found to be unpopular for many students ${ }^{6}$. However, research also suggests that attitudes towards psychiatry may be changed. For example, there is also some evidence that psychiatric courses may change the clinical behavior of physicians, so that the course would benefit their careers ${ }^{7}$.

We consider that the improvement on the attitude of students towards psychiatry may depend on both the psychiatry curriculum and on the development of innovative teaching strategies. While a number of reports in the international literature have approached the teaching of psychiatry in medical schools, the use of standardized assessment methods has not been the norm in most studies. The literature provides a variety of educational methods to train medical students in general or in specific areas, but this literature has been found to be of variable quality, so that the provision of guidance for development of curricula and medical education policy is inconsistent ${ }^{8}$.

We have previously reported the use of innovative methods to teach Psychosomatic and Liaison Psychiatry in the Medical School of Zaragoza, and found that teaching results, and student satisfaction measured with a standardized, original method were both posi- 
tive $^{9}$. In this background, the objective of this study is to try to test the conjecture that this same method will be confirmed as beneficial in the training of medical students in the field of general psychiatry both, for curriculum results and for students' satisfaction.

\section{Methods}

The content of this course on psychiatry for medical students has been considered to be adequate by external experts consulted. The course has a theoretical part, for lectureoriented sessions; a seminar part, to potentiate active participation and learning in small groups (SG); a practical, bed-side clinical teaching; and a research-oriented part. The contents of the theoretical, lecture-oriented part follows standard material in textbooks, such as the one we now recommend ${ }^{10}$. The teaching methodology of the full academic year course is summarized in table 1.
A crucial innovation in the last years was the introduction of the "Innovative Teaching Plan" for students (ITP) (http://www.unizar.es/ innovacion/convocatorias2010/index.php), intended to educate student-leaders to stimulate between-students interaction and participation. Over the last academic courses, a requirement for each SG was to design an original research project, led by the trained ITP.

Special consideration in the course had the bedside teaching. While the staff resources are limited for the number of students assigned each year and the heavy clinical responsibilities of clinicians, the Department managed itself to provide a 4-week period of bedside, practical supervised work for the students. Table 2 summarizes the main characteristics of this bedside teaching.

A central coordination for the program has been organized, under the responsibility of a motivated, clinical professor. Then, a teaching improvement plan was designed which includes characteristics such as an active super-

Table 1

Teaching methodology in the psychiatry courses.

- One full academic course per year, 9 UZ credits; 6.4 ECTS credits

- Two hours/week for classes/seminars

- 50\% lectures $/ 50 \%$ clinical cases seminars

- "Innovative Teaching Plan" for students (I.T.P.)

- Weekly session with I.T.P. student leaders

- "Small Groups" (SG) (n= 4 students) with I.T.P. leader in seminars

- One research project by SG and I.T.P. leader.

vision by tutors, with the students having online access; systematic meetings with students; specific supervision in taking the psychiatric history and one -to -one supervision by clinical professors throughout the clerkship.
Trainee performance has been assessed by the marks in the final examination, and the Medical Teaching Quality Questionnaire (MTQQ) ${ }^{11}$ was used to document trainee satisfaction. We originally developed the MTQQ 
Table 2

Bedside teaching of psychiatry: the philosophy.

- Central coordination by motivated, clinical professor

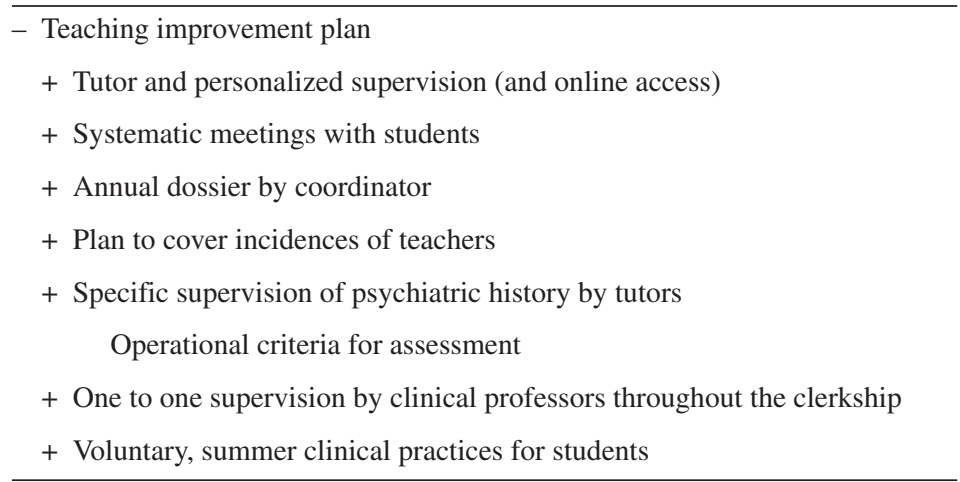

to capture the student's perception of salient aspects of teaching practices. It contains fivepoint, Likert-type items related to the subject matter; to the teaching method; and to the actual stimulation of research interest. Performance of teachers is also assessed, and a global satisfaction item is accessible to capture to what extent the course meets the student's expectations. The questionnaire also invites the student to answer open questions about "the two most positive" and "the two most negative" aspects of the course. Reliability of the MTQQ was considered to be "good to excellent" (Cronbach's alfa coefficient was 0.865 ; and test-retest kappa $\mathrm{W}$ was 0.655 (I.C. 99\% 0.562-0.748); and construct validity was also supported ${ }^{11}$.

All participating students completed anonymously the MTQQ in the last week of teaching. The questionnaires were then placed in a sealed envelope, under the custody of teachers and students' course representatives, to be open after the official marks were made public by the University officials. The results of the academic courses 2007-08 through 201112 with available assessments, and corres- ponding to one of the two groups in the class, are presented in this report.

MTQQ items were treated separately for the statistical analysis. Scores in each item have been combined into three categories, positive results or "above average" (AA: "high" or "very high"), "average" ("middle") and "below average". Descriptive, summary statistics are presented as frequencies and percentages for discrete variables, and means and standard deviations for continuous variables.

\section{Results}

External psychiatric professors from different medical schools have been consulted at different points in this process. They support the idea that the content of the course, was adequate. Eight hundred and thirty eight medical students have completed the learning course in the study period, and 418 (one of the two groups) completed the evaluation with the MTQQ. 
Most students $(85 \%-92 \%)$ took the first round of the final examination each year, and 93-95\% of them passed the examination. High marks, "outstanding" marks (9.0 or more, maximum 10 points) were obtained throughout this experience by $30 \%-33 \%$ of medical students, including among them 21 students with "honors".
In relation to satisfaction, figure 1 shows that more than three quarters the students scored above average (AA: "high" or "very high") the relevance of this subject for medical training, its usefulness for physicians or the quality of the scientific information provided, and the usefulness of the clinical cases was rated particularly high, with more than $90 \%$

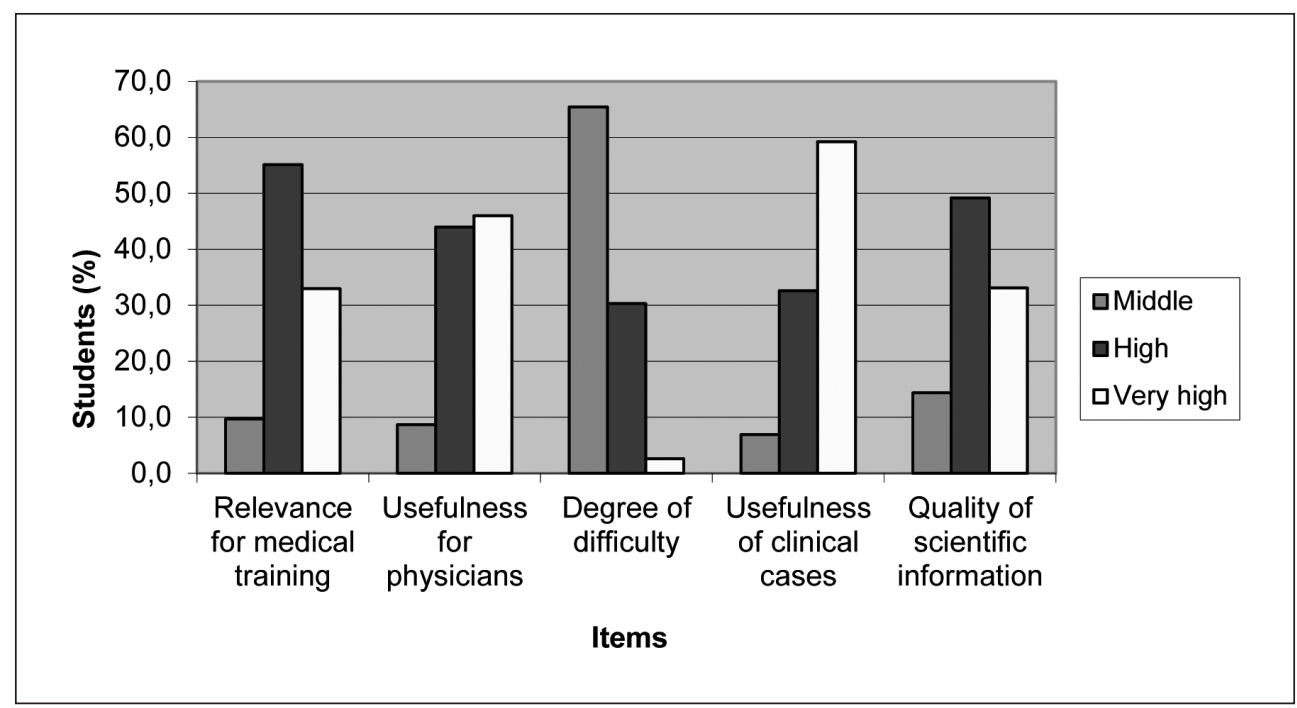

Figure 1. Assessment by medical students of the relevance and quality of contents in five consecutive academic courses of psychiatry. Mean scores in Medical Teaching Quality Questionnaire MTQQ.

scoring in those categories. Medical students considered the degree of difficulty of the subject was not particularly high, since only one third of them scored in the same categories.

In relation to the quality of the teaching methods, figure 2 shows that the technical mastery and the preparation of lectures were rated very favourably by medical students, since both items were rated "high" or "very high" (AA). "Clarity in teaching" was also rated in those categories by more than $2 / 3$ rds of students, but the study of bibliographical material was not so favourable, since only 1/4th rated "high" or "very high".
In relation to innovative teaching methods, "enhancement of a researcher's mind" was rated "high" or "very high" (AA) by $1 / 3^{\text {rd }}$ of medical students, and the remainder rated "middle" (average). The usefulness of the continued evaluation, with the assessment and tests performed in the classroom, in regular teaching hours, was rated in the high categories by more than $2 / 3$ rds the medical students.

The utility of the yearly evaluation of the quality of teaching methods was tested by observing the results in items rated not very positive in the first evaluation. Figure 4 shows the results of this longitudinal assessment in 


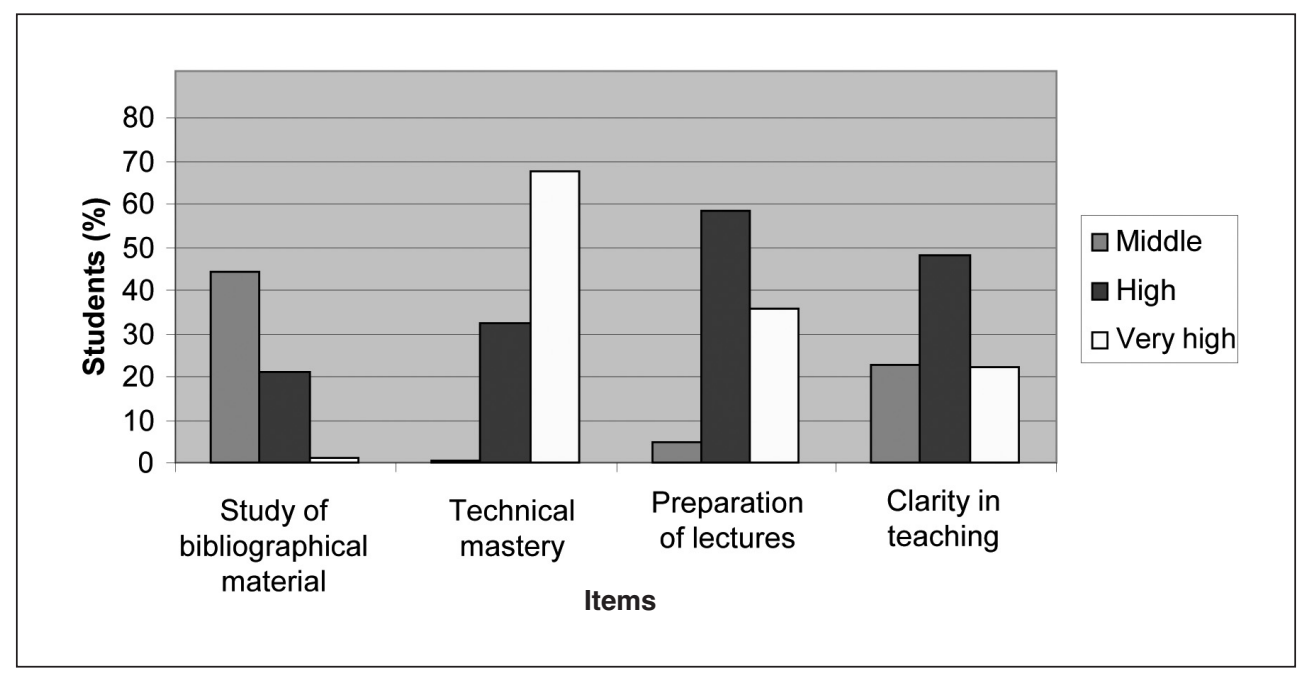

Figure 2. Assessment by medical students of the quality of teaching methods in five consecutive academic courses of psychiatry. Mean scores in Medical Teaching Quality Questionnaire MTQQ.

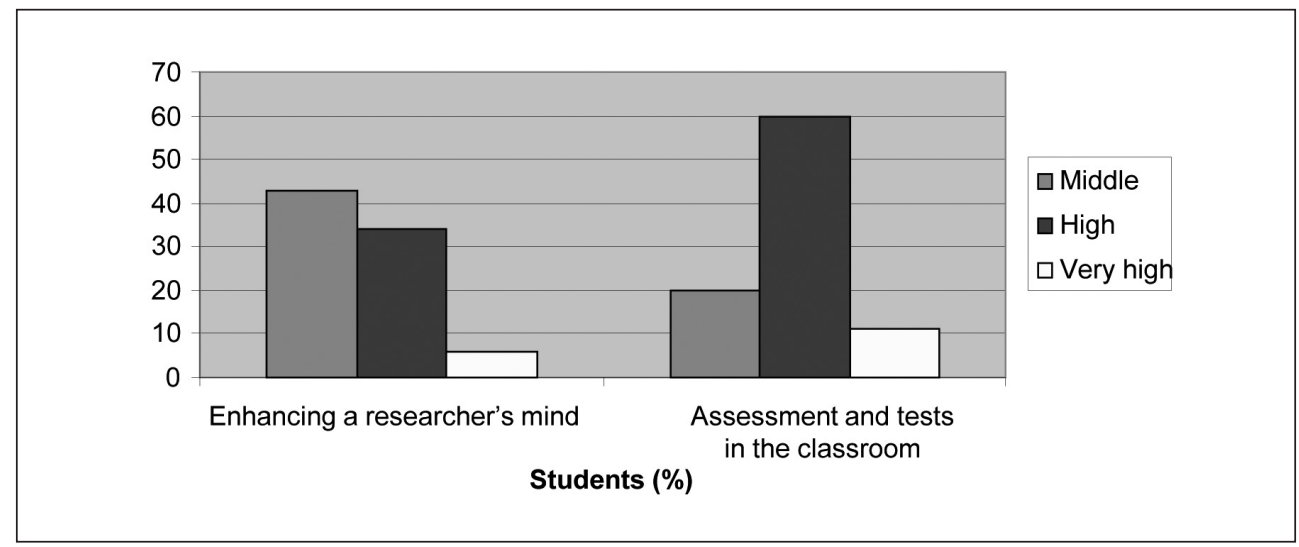

Figure 3. Assessment by medical students of innovative teaching methods in five consecutive academic courses of psychiatry. Mean scores in Medical Teaching Quality Questionnaire MTQQ.

relation to the "the clarity in teaching". It shows favorable results, since the proportion of students rating "very high" this item starts in a rather low proportion in the academic course 2007/08 (below 20\%). With this information coming from the enquiries, the teachers face somehow the situation and are able to show an improvement, so that the proportion of "very high" ratings increases gra- dually to above $40 \%$ in the academic course 2011/12.

Similarly, the utility of the yearly evaluation of the quality of teaching methods has also been tested in relation to the approach to enhance a researcher's mind. Figure 5 shows the results of this longitudinal assessment, also showing favorable results: the proportion 


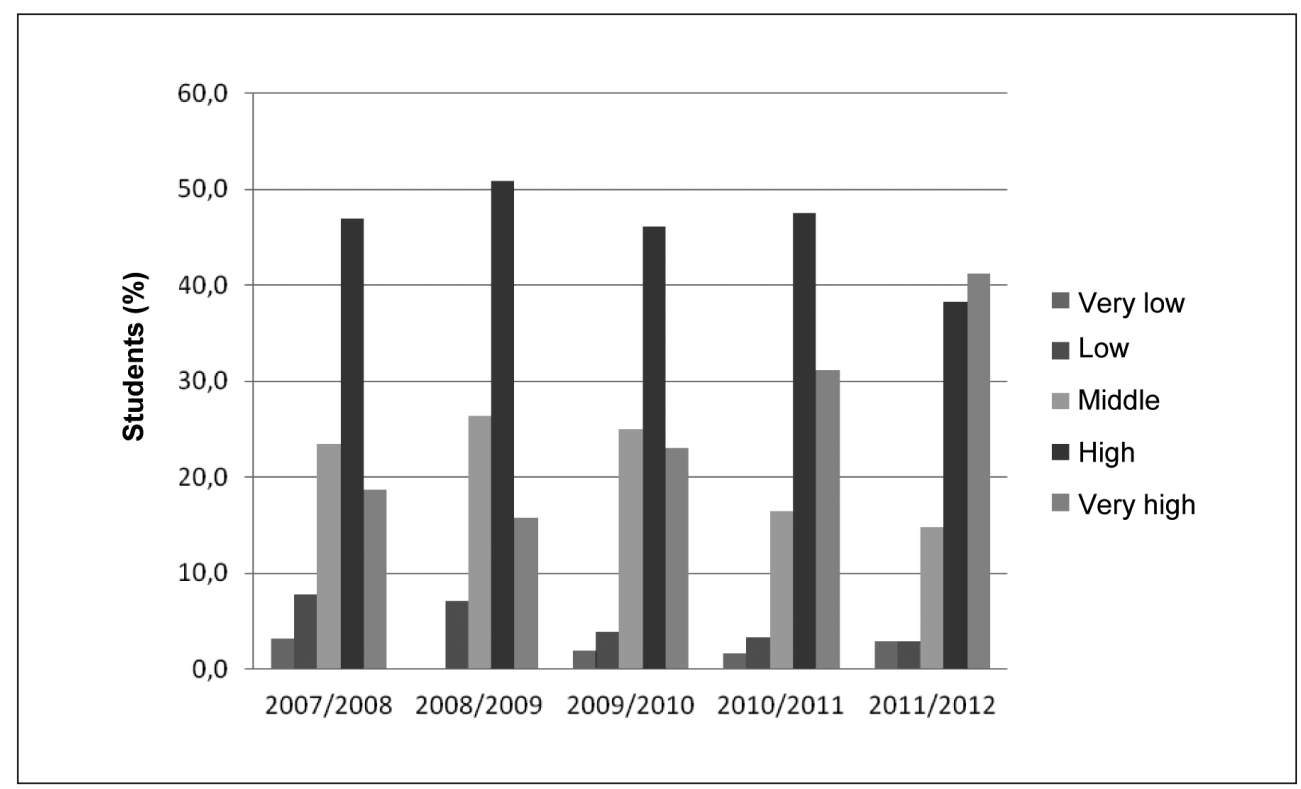

Figure 4. Progress in positive scores of medical students in assessing the clarity in teaching. Mean scores in Medical Teaching Quality Questionnaire MTQQ.

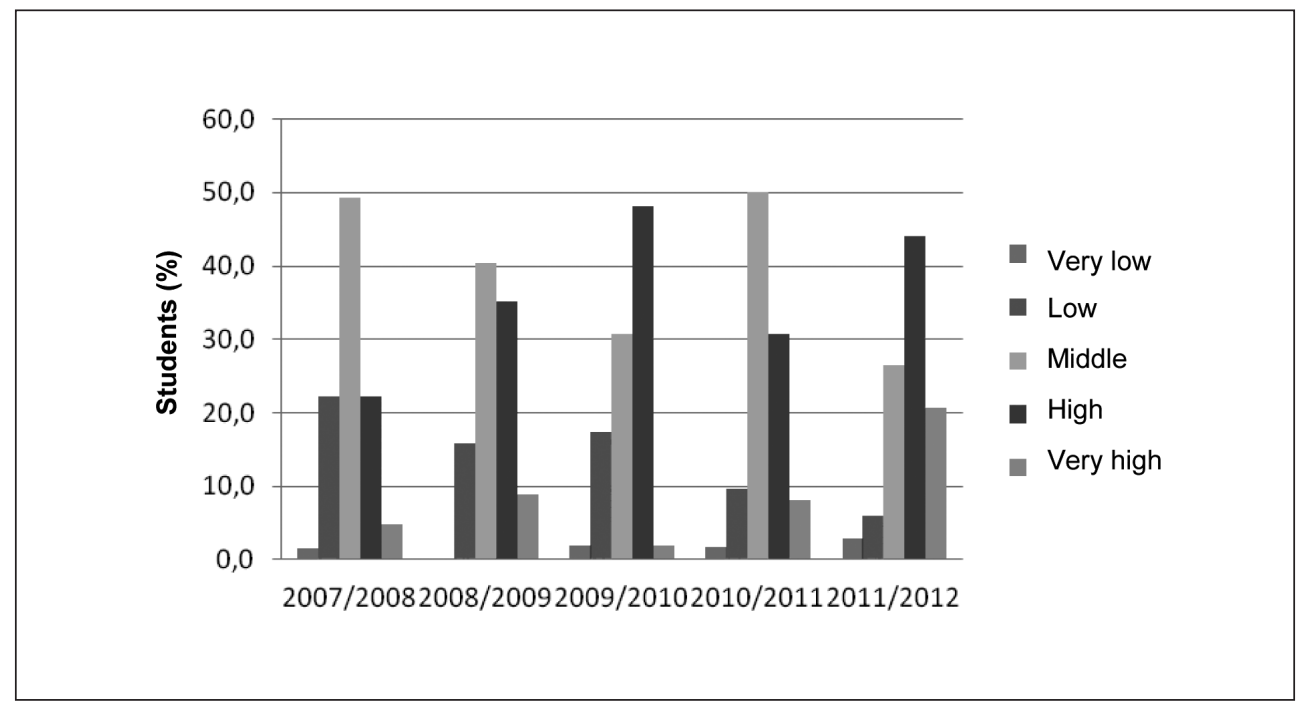

Figure 5. Progress in positive scores of medical students in assessing the approach to enhance a researcher's mind. Mean scores in Medical Teaching Quality Questionnaire MTQQ. 


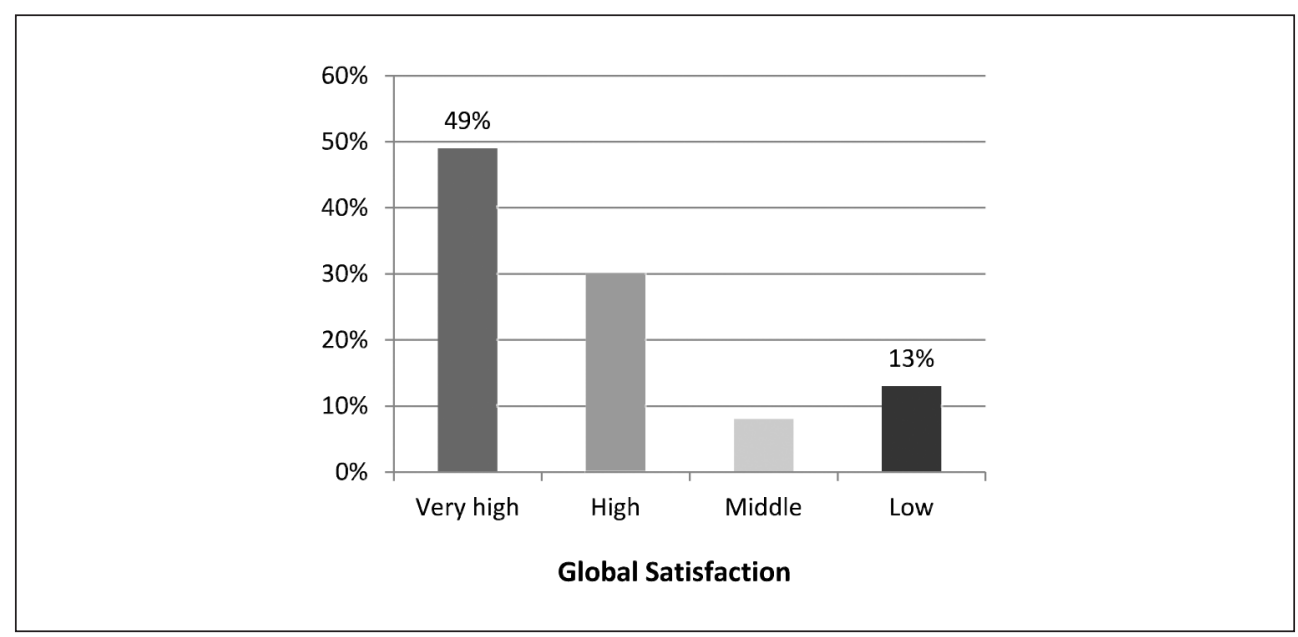

Figure 6. Assessment of the medical students' satisfaction with the bedside teaching. Mean scores in Medical Teaching Quality Questionnaire MTQQ.

of students rating "high" or "very high" (AA) this item starts in a low number in the academic course 2007/08 (approximately 25\%). Then, the teachers face somehow the situation and are able to show a gradual improvement, so that the proportion of the same ratings goes up to $2 / 3 \mathrm{rds}$ of students in the academic course 2011/12.

The MTQQ has also been used to asses the students' satisfaction with the bedside teaching during the last academic course in the study period. All students $(n=198)$ in the class completed this part of the study. Most students $(87 \%)$ rated "high" or "very high" (AA) this item in the questionnaire.

Among "the two most positive" aspects of the course, the students indicated most frequently the relevance of the subject and the discussion of clinical cases in small groups followed by the general discussion. Similarly, they had an exceptional, positive view of the bedside teaching.

\section{Discussion}

As most previous medical education research, this study has focused on the assessment of trainee performance and trainee satisfaction ${ }^{12}$, frequently used sources of information entering into the academic decision-making process $^{13}$. Our research has found support for the initial conjecture that the rather original method implemented for the training of medical students in general psychiatry is beneficial for both the final results of examinations in this subject and for the students' satisfaction.

The performance of trainees in this particular course was quite positive, since the great majority passed the first round of the final examination, and a considerable proportion was awarded high marks. These results compare favourably with other medical subjects in the same academic years (information from the medical school). The fact that most students 
rated the course as "no-difficult" (2/3rds) may partially explain the positive results.

In relation to the students' satisfaction, most items in the sections of relevance of the curriculum for a general physician; quality of the teaching methods; or specific methods such as the use of continued evaluation in the standard classes, were all rated very positively. The enhancement of the student-teacher interaction has also been rated positively in the final, open questions, and may merit special attention, since the desirability of this interaction has been supported in different studies ${ }^{14,15}$.

This report further documents that the inclusion of clinical cases in the teaching seminars was most favourably valued by the students. In fact, methods of teaching with cases are receiving increasing support ${ }^{16}$, and have been used to advance deeper learning in medical fields ${ }^{17}$. Our approach is quite similar in this respect to the valued method of problem-based learning $(\mathrm{PBL})^{18}$. We believe this method is also quite appropriate for learning clinical reasoning, particularly when the cases are worked-out in small groups under the leadership of specially trained medical students and the maintained supervision of the professor ${ }^{19}$. Clinical reasoning is considered to be a crucial aspect of medical training ${ }^{20}$.

We have also documented in this study the positive ratings of teachers' performance by the medical students. This may explain in part the student's general satisfaction, since approval by students has been documented to be highly related to the teachers' performance $^{21}$. Other aspect considered to be positive in this course is the inclusion of available, voluntary summer practices in clinical work $^{22}$. Moreover, we believe part of the students' satisfaction may be related to our commitment to teach especially on the recognition and treatment of those common mental disorders that they will have to face fre- quently in their medical practice. This makes sense to them, obviously, and has been emphasized as one of the goals in the future of medical education ${ }^{23}$.

An important aspect in the course is certainly the bedside teaching. In relation to this, the appointment as coordinator of a highly motivated, clinical professor (RC) has been crucial to promote the plan; and to stimulate a personalized supervision. We consider the very positive rating in this section is quite remarkable, particularly because the time allotment for bedside teaching, a 4-week clerkship, is limited, and the supervisors are particularly burdened with clinical care. A special consideration in the bedside teaching was given to the improvement in the ability of students to collect psychiatric histories, an important aspect of medical training ${ }^{18}$.

The positive rating in "enhancing a researcher's mind" merits emphasis, since innovation and research is certainly crucial in Medicine. It is quite remarkable that the students were able to produce original research protocols, with only limited training, although we have previously documented similar results in Psychosomatic Psychiatry ${ }^{9}$. As we have previously suggested, an explanation to this performance may be related to the high quality of medical students in countries such as Spain, where the acceptance in medical schools requires very high marks (http://wzar. unizar.es/servicios/acceso/admisgrado/corte/gr ados11-12.pdf). However, we believe it also relates to the clear message sent to trainees about the relevance of research, and the commitment to stimulate the initiative and the potential of such bright students. Research activity is not a mandatory component of medical education in Spain, and similarly in other countries, although some previous reports underlie the fact that most students are interested in research and complain of the lack of institutional incentive ${ }^{24}$. 
Contrary to the positive aspects, most students rated low initially the items related to "out of classroom" (not in-person) work with bibliography material. While this type of study is valued by the teachers, particularly aiming at continuous, post-graduate education, it seems obvious that changes in this methodology had to be introduced should the objective be to make it more attractive for the students. On the bases of this observation, we modified the teaching method, with some positive results. Similarly, we show in this study that it was possible to improve the students' satisfaction in relation to the "clarity" of lectures, by modifying the method in the following courses once we were aware of the unsatisfactory results. This observation supports the importance of this type of research, since weak aspects of the teaching method may be identified so that remedial action can be implemented.

Among the strengths of the study we include the use of a reliable and valid assessment instrument and the longitudinal design, with a five-year evaluation. We also value the innovative method introduced by training I.T.P. students as leaders in the SGs, and also in the development of the original research designs. Students responses to the final, open questions in the MTQQ support this interpretation.

Limitations in the study should also be addressed. First, the results in one medical school, although it is rather typical in Spain, may not be generalizable, and the methods should be implemented elsewhere before they have more general acceptance. And second, it has been shown that medical students may be only moderately consistent in the extent to which they evaluate teachers, and the inconsistency may vary by course and by teachers within the courses ${ }^{13}$. However, this potential bias is minimized in this study, because different academic courses were assessed and results were consistent.
Few other subjects may be addressed, looking at the future. The teaching of specific areas of psychiatry, such as child and adolescent psychiatry ${ }^{25}$, competent psychopharmacology ${ }^{26}$, community psychiatry ${ }^{27}$ or substance abuse ${ }^{8}$ may need a more detailed analysis. We are particularly interested in the potential role of trainees as clinical teachers of medical students in psychiatry ${ }^{28}$; and are also supportive of the need to try to homogenize the core curricula across medical schools $^{23}$. Finally, we are also convinced, as our teachers McHugh and Slavney ${ }^{29}$, that teaching psychiatry may provide notable pleasure and lasting satisfaction ${ }^{30}$.

In conclusion, the conjectures about the advantages of our method in teaching psychiatry for medical students are supported by the results presented and discussed. In view of the positive assessment of this course, this study also may draw lessons to inform medical teachers about efficient and effective ways of teaching and learning psychiatry.

\section{Co-authors}

H. Salvador-Rosés, L.Lobo-Escolar, M.J. Pérez Echevarría, M. Cortina, J. Civeira, J.L. Día, J. García Campayo, I. Irigoyen, A. Pérez Poza, M.A. Quintanilla, P. Ruiz, C. Sanz, M. Velilla, M.A. Zapata.

\section{Acknowledgements}

Special recognition should be given to the following medical students who did excellent work as the leaders of small groups in the "Innovative Teaching Plan" (ITP): H. Salvador-Rosés, L. Lobo Escolar, E. Esparza 
Isasa, L. Gil Melgosa, F. Fuentes Gorgas, A. Lambea Gil, B. Apellániz Aparicio, G. Pírez Mora, H. López Mendoza, M.E. Calvo Cotado, Z. Carrillo López, M. Marco Brualla, I. Abadías Granados, H. Arasanz Esteban, I. Hernández Aragüés, J.A. Delgado Domingo, M. González Sierra, B. Gros Alcalde.

\section{References}

1. Platt L. Medical science: Master or servant? Br Med J. 1967; 4(5577): 439-44.

2. Kelly B, Raphael B, Byrne G. The evaluation of teaching in undergraduate psychiatric education: Students' attitudes to psychiatry and the evaluation of clinical competency. Med Teach. 1991; 13(1): 77-87.

3. Levine RE, O'Boyle M, Haidet P, Lynn DJ, Stone MM, Wolf DV, Paniagua FA. Transforming a clinical clerkship with team learning. Teach Learn Med. 2004; 16(3): 270-5.

4. Castle D, Sanci L, Hamilton B, Couper J. Teaching psychiatry to undergraduates: Peer-peer learning using a "GP letter". Acad Psychiatry. 2014; 38(4): 433-7.

5. Goerg D, De Saussure C, Guimón J. Objectives for the undergraduate teaching of psychiatry: Survey of doctors and students. Med Educ. 1999; 33(9): 639-47.

6. Lyons Z. Attitudes of medical students toward psychiatry and psychiatry as a career: A systematic review. Acad Psychiatry. 2013; 37(3): 150-7.

7. Halperin PJ. Psychiatry in Medicine: Five years of experience with an innovative required fourth-year medical school course. Acad Psychiatry. 2006; 30(2): 120-5.

8. Kothari D, Gourevitch MN, Lee JD, Grossman E, Truncali A, Ark TK, Kalet AL. Undergraduate medical education in substance abuse: A review of the quality of the literature. Acad Med. 2011; 86(1): 98-112.

9. Lobo A, Campayo A, de-la-Cámara C, Saz P, Salvador H, Lobo-Escolar L, López-Mendoza H, Pírez G, Calvo ME, Ventura T, Lobo E, Marco C. The teaching of liaison psychiatry. J Psychosom Res. 2012; 72(6): 457-9.

10. Lobo A. Manual de Psiquiatría. Editorial Médica Panamericana. Madrid. 2013.

11. Saz P, Campayo A, Lobo E, Aguilar E, De-La-Fuente $\mathrm{S}$, Lobo A. Psychometric properties of a teaching evaluation questionnaire for an Academic Psychiatric Area. Educación Médica. 2007; 10(2): 121-126.
12. Prystowsky JB, Bordage G. An outcomes research perspective on medical education: The predominance of trainee assessment and satisfaction. Med Educ. 2001; 35(4): 331-336.

13. West RF. The short-term stability of student ratings of instruction in medical school. Med Educ. 1988; 22(2): 104-12.

14. Young L, Orlandi A, Galichet B, Heussler H. Effective teaching and learning on the wards: Easier said than done. Med Educ. 2009; 43(8): 808-17.

15. Jaarsma AD, Dolmans DD, Muijtjens AM, Boerboom TT, van Beukelen P, Scherpbier AJ. Students' and teachers' perceived and actual verbal interactions in seminar groups.Med Educ. 2009; 43(4): 368-76.

16. Boehrer J, Linsky M. Teaching with Cases: Learning to Question. In M.D. Svinicki (ed.). The Changing Face of College Teaching. New Directions for Teaching and Learning, 42. San Francisco: Jossey-Bass, 1990.

17. Zimmerman SD, Lester Short GF, Hendrix EM. Impact of interdisciplinary learning on critical thinking using case study method in allied health care graduate students. J Allied Health. 2011; 40(1): 15-8.

18. Schäfer M, Georg W, Mühlinghaus I, Fröhmel A, Rolle D, Pruskil S, Heinz A, Burger W. [Experience with new teaching methods and testing in psychiatric training]. Nervenarzt. 2007; 78(3): 283-4, 287-90, 292-3.

19. Harris A, Boyce P, Ajjawi R. Clinical reasoning sessions: Back to the patient. Clin Teach. 2011; 8(1): 13-6.

20. Schatte DJ, Piemonte N, Clark M. "I Started to Feel Like a 'Real Doctor'": Medical Students' Reflections on Their Psychiatry Clerkship. Acad Psychiatry. 2015.

21. Schüppel R, Gatter J, Hrabal V. Teaching psychosomatic medicine: Predictors of students' attitudes toward a compulsory course. J Psychosom Res. 1997; 42(5): 481-4.

22. Black ML, Curran MC, Golshan S, Daly R, Depp C, Kelly C, Jeste DV. Summer research training for medical students: Impact on research self-efficacy. Clin Transl Sci. 2013; 6(6): 487-9.

23. Thomas S, Pai N, Dawes K, Wilson C, Williams V. Updating medical school psychiatry curricula to meet projected mental health needs. Australas Psychiatry. 2013; 21(6): 578-82.

24. De Oliveira NA, Luz MR, Saraiva RM, Alves LA. Student views of research training programmes in medical schools. Med Educ. 2011; 45(7): 748-55.

25. Hunt J, Barrett R, Grapentine WL, Liguori G, Trivedi HK. Exposure to child and adolescent psychiatry for medical students: Are there optimal "teaching perspectives"? Acad Psychiatry. 2008; 32(5): 357-61. 


\section{ANTONIO LOBO ET AL.}

26. Gardner DM. Competent psychopharmacology. Can J Psychiatry. 2014; 59(8): 406-11.

27. Abed R, Teodorczuk A. Danger ahead: Challenges in undergraduate psychiatry teaching and implications for community psychiatry. Br J Psychiatry. 2015 Feb; 206(2): 89-90.

28. Hickie C, Nash L, Kelly B. The role of trainees as clinical teachers of medical students in psychiatry. Australas Psychiatry. 2013; 21(6): 583-6.

29. McHugh, P.R. and Slavney, Phillip R. The Education of Psychiatrists. In: New Oxford Textbook of Psychiatry, Gelder, M.G., Lopez-Ibor, J.J., Andreasen, N. (Eds.), Oxford University Press, 41-47, 2000.
30. Yager J. Personal reflections on a life of learning and teaching psychiatry. Int Rev Psychiatry. 2013; 25(3): 357-63.

\author{
Corresponding author: \\ Antonio Lobo \\ University of Zaragoza \\ Department of Medicine and Psychiatry \\ C/ Domingo Miral s/n \\ 50009 Zaragoza \\ Spain \\ Tel: +34976761713 \\ E-mail: alobo@unizar.es
}

